\title{
Adolescent opiate exposure in the female rat induces subtle alterations in maternal care and transgenerational effects on play behavior
}

\author{
Nicole L. Johnson, Lindsay Carini, Marian E. Schenk, Michelle Stewart and Elizabeth M. Byrnes*
}

Department of Biomedical Science, Cummings School of Veterinary Medicine, Tufts University, North Grafton, MA, USA

Edited by:

Josephine Johns, University of North

Carolina at Chapel Hill, USA

Reviewed by:

Rina Eiden, University at Buffalo, USA

Craig H. Kinsley, University of

Richmond, USA

*Correspondence:

Elizabeth M. Byrnes, Section of Neuroscience and Reproductive Biology, Department of Biomedical Science, Cummings School of Veterinary Medicine, Tufts University, 200 Westboro Road, North Grafton, MA 01536, USA.

e-mail: elizabeth.byrnes@tufts.edu
The non-medical use of prescription opiates, such as Vicodin ${ }^{\circledR}$ and MSContin ${ }^{\circledR}$, has increased dramatically over the past decade. Of particular concern is the rising popularity of these drugs in adolescent female populations. Use during this critical developmental period could have significant long-term consequences for both the female user as well as potential effects on her future offspring. To address this issue, we have begun modeling adolescent opiate exposure in female rats and have observed significant transgenerational effects despite the fact that all drugs are withdrawn several weeks prior to pregnancy. The purpose of the current set of studies was to determine whether adolescent morphine exposure modifies postpartum care. In addition, we also examined juvenile play behavior in both male and female offspring. The choice of the social play paradigm was based on previous findings demonstrating effects of both postpartum care and opioid activity on play behavior. The findings revealed subtle modifications in the maternal behavior of adolescent morphine-exposed females, primarily related to the amount of time females' spend nursing and in non-nursing contact with their young. In addition, male offspring of adolescent morphine-exposed mothers (MOR-F1) demonstrate decreased rough and tumble play behaviors, with no significant differences in general social behaviors (i.e., social grooming and social exploration). Moreover, there was a tendency toward increased rough and tumble play in MOR-F1 females, demonstrating the sex-specific nature of these effects. Given the importance of the postpartum environment on neurodevelopment, it is possible that modifications in maternal-offspring interactions, related to a history of adolescent opiate exposure, plays a role in the observed transgenerational effects. Overall, these studies indicate that the long-term consequences of adolescent opiate exposure can impact both the female and her future offspring.

Keywords: morphine, offspring, rough and tumble play, nursing, maternal attachment

\section{INTRODUCTION}

Since the early 1990s there has been a steady increase in prescription rates for opiates (Substance Abuse and Mental Health Services Administration [SAMHSA], 2009), including prescribing for conditions ranging from routine dental procedures to menstrual cramps. This escalation in prescribing, coupled with increased availability of these substances online (Forman et al., 2006), and the advent of long-acting forms of opiate analgesics such as OxyContin ${ }^{\circledR}$, have combined to create a dangerous upsurge in both the medical and non-medical use of prescription pain medications (Paulozzi et al., 2006; Cai et al., 2010). Of great concern is the increased use of these potent opiates in adolescent populations (Sung et al., 2005), with $60.6 \%$ of respondents in a recent survey reporting initiation of use before the age of 15 (Wu et al., 2008). Misuse in younger populations is likely due to the decreased risk perception associated with prescription opiates (e.g., as compared to heroin), in conjunction with their increased availability. Indeed, overall, prescription drugs are reported as the "drug of choice" in 12- and 13-yearold populations (SAMHSA, 2007) and unlike other drugs of abuse, they are used at higher rates in young female populations
(Sung et al., 2005; Alemagno et al., 2009). Currently, the longterm impact of this increased use of opiates in adolescent female populations remains unknown.

Given that adolescence represents a period of significant brain maturation, perturbation of the endogenous opioid system during this period may induce significant long-term effects. Endogenous opioids (beta-endorphin, dynorphin, and enkephalin) and their receptor targets (mu, kappa, and delta) are ubiquitous, serving as critical modulators of neural, endocrine, and immune function. For example, during adolescence, endogenous opioids modulate the timing of sexual maturation (Cicero et al., 1986; Reiter, 1987; Sizonenko, 1987). Opioids also regulate stress responsiveness as well as modulating numerous cognitive and reward-related processes (Zager and Black, 1985; McCubbin, 1993; Van Ree et al., 2000; Drolet et al., 2001; Kreek, 2007). Thus, adaptations in response to high levels of opioids during adolescent development could impact a wide-range of opioid-mediated functions.

A significant body of literature indicates that endogenous opioids play a role in maternal behavior. Initial studies conducted with morphine, showed a disruption of postpartum maternal behavior (Bridges and Grimm, 1982; Rubin and Bridges, 1984; 
Kinsley and Bridges, 1986, 1990; Mann et al., 1990; Kinsley et al., 1995; Sukikara et al., 2007). These disruptive effects were even more pronounced when the female was pre-exposed to morphine during pregnancy (Bridges and Grimm, 1982; Miranda-Paiva et al., 2001; Slamberova et al., 2001). In a number of species, including humans and non-human primates, endogenous opioids modulate affiliative behaviors, including mother-infant attachment (Panksepp et al., 1994; Kalin et al., 1995; Nelson and Panksepp, 1998; Saltzman and Maestripieri, 2010). Indeed, there is evidence in women, that opioid use (e.g., methadone) can induce subtle alterations in mother-infant contact and attachment (Goodman et al., 1999). Moreover, studies indicate that endogenous opioids in both the mother, and the infant, are important for infant emotional regulation and attachment (Schino and Troisi, 1992; Weller and Feldman, 2003; Barr et al., 2008). If this system is altered by prior exposure to opiates, then postpartum maternal-offspring interactions could be affected.

We have previously documented significant effects of adolescent morphine exposure on the expression of opioid-related genes, including increased expression of mu- and kappa-opioid receptor genes and decreased expression of the proopiomelanocortin gene in the mediobasal hypothalamus (Byrnes, 2008). In addition, we observed attenuated suckling-stimulated prolactin secretion during early lactation in these females (Byrnes, 2005b, 2008). These findings demonstrate long-term changes in the endogenous opioid system of adolescent-exposed females, as well as alterations in physiological parameters that can influence maternal care. One additional component of these studies was an examination of rudimentary aspects of maternal behavior, such as the latency to retrieve and crouch over pups following a brief separation. No differences in maternal behavior latencies were observed, however, such measures do not assess quantitative or qualitative aspects of maternal care.

In addition to observing direct effects of adolescent morphine exposure on the female rat, we have also demonstrated transgenerational effects in both male and female offspring. These offspring effects include differences in anxiety-like behavior, shifts in morphine sensitization and alterations in morphine analgesia (Byrnes, 2005a; Byrnes et al., 2011). It is important to note that all adolescent-exposed females in our studies are drug-free for several weeks prior to mating. Thus, the developing embryo/fetus is never directly exposed to morphine. These findings indicate that even when morphine exposure is confined to the adolescent period, there can be significant effects on future offspring. Moreover, the nature of these transgenerational effects suggests an alteration in the endogenous opioid system of the offspring. Variations in maternal care can significantly impact offspring neurodevelopment, including the development of the endogenous opioid system (Weaver et al., 2007; Gustafsson et al., 2008; Michaels and Holtzman, 2008). Thus, one potential mechanism underlying transgenerational effects of adolescent morphine exposure may be altered maternal-offspring interactions.

The current study was designed to examine maternal behavior in females exposed to morphine during adolescent development. In addition, we also investigated social play behavior in their male and female offspring. The choice of social play behavior was based upon studies indicating that play behavior is modulated by opioids (Niesink and Van Ree, 1989; Vanderschuren et al., 1995; Van den
Berg et al., 2000) and can be altered by changes in the postnatal environment (Janus, 1987; Veenema and Neumann, 2009). Our working hypothesis is that adolescent morphine exposure induces significant changes in the endogenous opioid system of both the female and her offspring.

\section{MATERIALS AND METHODS EXPERIMENTAL ANIMALS}

Sixty female Sprague-Dawley rats (22 days of age) were purchased from Charles River Breeding Laboratories [Crl:CD(SD)BR; Kingston, NY, USA]. All animals were group-housed in light- (on 0700-1900 hours) and temperature- $\left(21-24^{\circ} \mathrm{C}\right)$ controlled rooms and provided with food and water ad libitum. All animals were maintained in accordance with the National Research Council (NRC) Guide for the Care and Use of Laboratory Animals and all procedures were approved by the Institutional Animals Care and Use Committee of Tufts University.

\section{ADOLESCENT MORPHINE EXPOSURE}

Beginning at 30 days of age, females were treated with morphine (morphine sulfate; Butler-Schein, Dublin, OH, USA) for a total of 10 days using an increasing dose regimen. The doses used in the current study were based on allometric scaling to approximate human use (Chiou et al., 1998). Moreover, the use of increasing doses is more compatible with human use patterns, allowing for rising and falling levels of opiates. On day 1 of exposure, 30 animals received $5 \mathrm{mg} / \mathrm{kg}$ morphine sulfate (s.c.) once daily (between 0900 and 1100 hours). Every other day, the dose of morphine was increased by $5 \mathrm{mg} / \mathrm{kg}$ such that by the final day of treatment subjects received $25 \mathrm{mg} / \mathrm{kg}$. Thirty, age-matched control animals received the saline vehicle $(0.9 \% \mathrm{NaCl}$, s.c. $)$ with volumes adjusted to match those of drug-treated females. Bodyweights were recorded daily throughout the treatment. Bodyweight gain during drug exposure was calculated by subtracting each animal's bodyweight on exposure day 1 from their bodyweight on exposure day 10. Bodyweight gain was also measured at additional time points post-withdrawal $(1,2,12$, and 19 days after withdrawal). Again, bodyweight gain was calculated relative to exposure day 1 (i.e., prior to their first injection). Adolescent-exposed females will subsequently be referred to as SAL-F0 and MOR-F0 females.

\section{MATING AND MATERNAL BEHAVIOR OBSERVATIONS - FO FEMALES}

At 60 days of age (i.e., 3 weeks after their final injection), SAL-F0 and MOR-F0 females were mated with colony males. A total of 27 SAL-F0 and 28 MOR-F0 became pregnant. The day of parturition was designated as postnatal day 0 (PND0). On PND1 all litters were weighed and culled to 10 pups (five males: five females). In a subset of these females, home-cage maternal behavior was observed at multiple time points throughout PND4, PND10, and PND16. A behavioral checklist was used to monitor maternal behavior with frequencies recorded every $60 \mathrm{~s}$ during a 30-min observation period. A total of five observation periods per day were included; three during the light phase (0900, 1200 , and 1500 hours), and two during the dark phase ( 0500 and 2000 hours). Behaviors monitored included nesting (in nest with pups regardless of nursing status), nursing (actively nursing at least one pup), pup grooming, and selfdirected behaviors (eating, drinking, self-grooming). In addition, 
on PND5 and PPD12 maternal behavior was digitally recorded for 30 min during the light phase (0800 hours; $1 \mathrm{~h}$ after lights on) or the dark phase (2000 hour; $1 \mathrm{~h}$ after lights off). Maternal behavior durations were then scored. The behaviors included the following: nursing (arched back, side, or low posture), hovering (female is in the nest but no pups are nursing), pup grooming, and self-directed behavior. Care was taken to minimize any disturbance to mothers and litters during these home-cage observations. Sample sizes for frequency data were 15 SAL-F0 and 18 MOR-F0 mothers, sizes for the video analysis were 12 SAL-F0 and 10 MOR-F0 mothers.

\section{SOCIAL PLAY TESTING - F1 MALES AND FEMALES}

On PND21 all litters from F0 mothers were weighed and weaned. F1 male and female offspring were then group-housed with same sex siblings. Between PND24 and 26, SAL-F1 and MOR-F1 males and females were tested for social play behavior in a novel environment. Only one male and one female per litter were used in social play testing to eliminate potential litter effects. On the day of testing, animals were socially isolated in a holding cage for $3.5 \mathrm{~h}$. Following isolation, unfamiliar subject pairs of the same sex and maternal adolescent exposure condition (i.e., SAL-F1 or MOR-F1) were placed in a novel test chamber $(40 \mathrm{~cm} \times 30 \mathrm{~cm} \times 60 \mathrm{~cm})$ under dim lighting conditions. Behavior was then digitally recorded for $15 \mathrm{~min}$. Sample size was based on pairs, with each pair scored for the frequency and duration of select play behaviors using ODlog software. The scored behaviors included the following: boxing/wrestling, pinning, chasing/following, crawling over/under, social exploration (sniffing any part of the conspecific), and social grooming. Sample sizes were 10 SAL-F1 male and 10 SAL-F1 female pairs; 12 MOR-F1 male and 12 MOR-F1 female pairs. These subjects represent data from $N=20$ SAL-F0 litters and $N=24$ MOR-F0 litters.

\section{STATISTICAL ANALYSES}

Differences in bodyweight gain during the morphine exposure regimen were analyzed using a Student's $t$-test. Post-withdrawal bodyweight gain was analyzed using a two-way repeated-measures ANOVA with day as the within subject factor and drug exposure (SAL or MOR) as the between-subject factor. Maternal behavior frequency data were analyzed using a two-way repeated-measures ANOVA with phase of the light cycle as the within subject factor and adolescent maternal exposure as the between-subject factor. Each postnatal day was analyzed separately. Social play behavior data was analyzed using a two-way ANOVA with sex and adolescent maternal exposure (SAL-F1 versus MOR-F1) as factors. All significant effects were followed by post hoc analyses using the Tukey's test. For all data, significance was designated as $p<0.05$.

\section{RESULTS}

\section{EFFECTS OF ADOLESCENT MORPHINE EXPOSURE ON BODYWEIGHT}

All females continued to gain weight during the 10-day injection regimen $(\mathrm{SAL}-\mathrm{F} 0=51.8 \pm 1.2 \mathrm{~g} ; \mathrm{MOR}-\mathrm{F} 0=43.8 \pm 0.89 \mathrm{~g})$, however, MOR-F0 females gained significantly less than SAL-F0 controls $\left[t_{(58)}=-5.43, p<0.001\right]$. Attenuated bodyweight gain continued to be observed when measured soon after drug-withdrawal, but these differences did not persist at later time points [day $\times$ drug interaction; $\left.F_{(3,179)}=4.5, p<0.01\right]$. As shown in Figure 1, MOR-F0 females had reduced weight gain on the first 2 days following withdrawal,

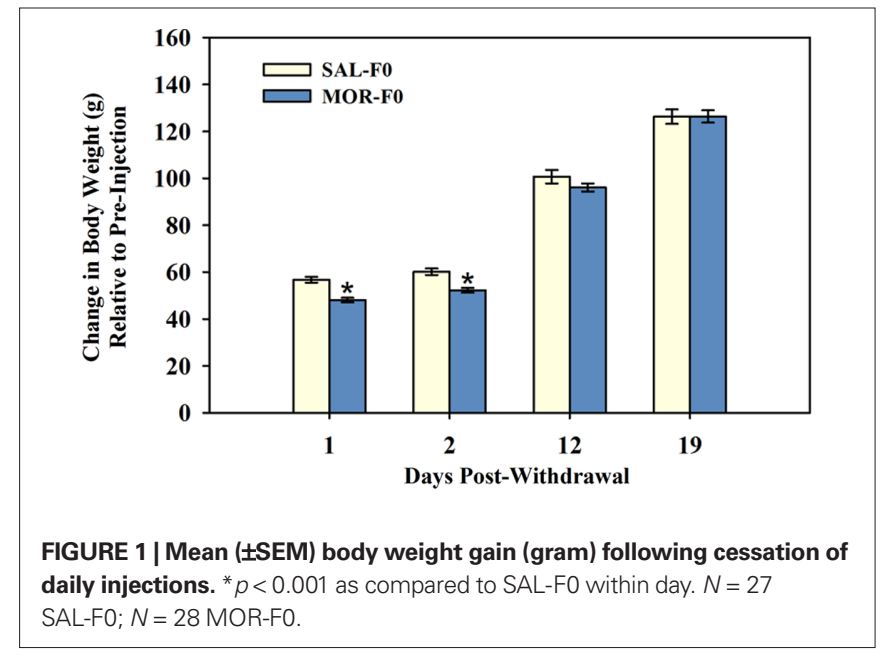

however, by the 12th day post-withdrawal these differences were no longer observed. Prior to mating (i.e., 20 days post-withdrawal), all females were of similar weights.

Data recorded on PND1 did not reveal any significant differences in litter size, gender ratio, or total litter weight (all $p s>0.2$ ). At weaning (PND21) there was a significant difference between the groups, with MOR-F1 subjects weighing more than SAL-F1 controls $\left[t_{(53)}=2.17, p<0.05\right]$. These data are reported in Table 1. As post-culling bodyweights were not taken on PND1, we were unable to determine whether MOR-F1 pups that remained post-culling were heavier. Thus, whether these differences reflect increased bodyweight gain in MOR-F1 pups during the postnatal period remains to be determined.

\section{MATERNAL BEHAVIOR IN ADOLESCENT MORPHINE-EXPOSED FEMALES - FREQUENCIES}

All maternal behavior frequency data are presented in Figure 2. On PND4, there was a main effect of light phase $\left[F_{(1,31)}=55.4\right.$, $p<0.001]$, adolescent exposure $\left[F_{(1,31)}=6.9, p<0.02\right]$, as well as a significant interaction $\left[F_{(1,31)}=4.3, p<0.05\right]$ on the frequency of nursing behavior. Specifically, all females showed reduced nursing during the dark phase, however, MOR-F0 mothers nursed less frequently during the dark phase $(p<0.01)$. On PND10 there was a main effect of light phase $\left[F_{(1,31)}=11.0, p<0.001\right]$, with no other significant effects. Finally, on PND16 there was both a main effect of light phase $\left[F_{(1,31)}=9.4, p<0.01\right]$ and a significant interaction $\left[F_{(1,31)}=5.2, p<0.05\right]$. Post hoc analyses indicate that SAL-F0 mothers nursed less frequently during the dark phase, while MOR-F0 mothers did not reduce nursing frequency during the dark phase.

The decreased frequency of nursing observed in MOR-F0 was related to an increase in their frequency away from the nest. As shown in Figure 2, MOR-F0 mothers tended to be away from their nests more frequently than SAL-F0 mothers during the dark phase. On PND4, there was a main effect of light phase $\left[F_{(1,31)}=71.2\right.$, $p<0.001]$ as well as a significant interaction $\left[F_{(1,31)}=6.9, p<0.02\right]$. All females were off the nest more frequently during the dark, however, this effect was significantly greater in MOR-F0 mothers $(p<0.01)$. On PND10 there was a main effect of both light phase $\left[F_{(1,31)}=119.9, p<0.001\right]$ and adolescent exposure $\left[F_{(1,31)}=4.3\right.$, 
Table 1 |The effects of adolescent morphine exposure on postnatal parameters.

\begin{tabular}{lllll}
\hline & Litter size (no. of pups) & No. of females & No. of males & Bodyweight (g, PND1) \\
\hline SAL-F0 & $14.1 \pm 0.5$ & $6.7 \pm 0.4$ & $7.4 \pm 0.4$ & $91.2 \pm 2.7$ \\
MOR-F0 & $14.2 \pm 0.4$ & $7.5 \pm 0.3$ & $6.6 \pm 0.5$ & $96.5 \pm 2.3$
\end{tabular}

${ }^{*} p<0.05$ as compared to SAL-FO on PND21.

$p<0.05]$, with MOR-F0 off the nest more frequently than SAL-F0 mothers. Finally, on PND16 there was a main effect of light phase $\left[F_{(1,31)}=30.86, p<0.001\right]$ and a significant interaction $\left[F_{(1,31)}=7.16\right.$, $p<0.02]$. Post hoc analyses indicate an increased frequency for MOR-F0 mothers to be away from the nest when compared to SAL-F0 mothers during the light phase only.

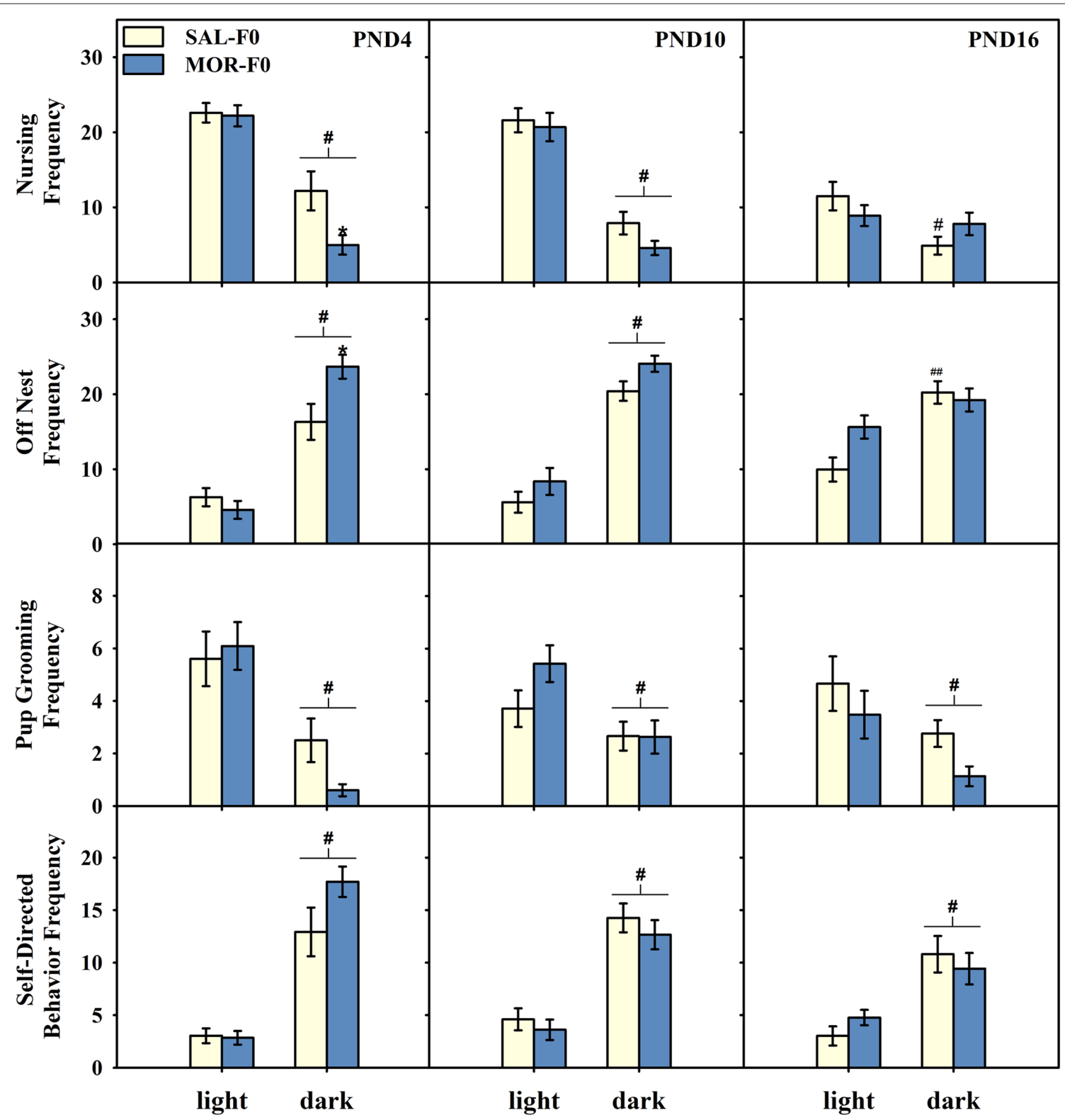

FIGURE 2 | Mean (士SEM) frequency nursing, off nest, pup grooming, or engaged in self-directed behaviors on PND4, 10, and 16. Data collected during the light phase was averaged across three observation periods $(0900,1200$, and 1500 hours). Data collected during the dark phase was averaged across two observation periods (0500 and 2000 hours). ${ }^{\#} p<0.01$ compared to light phase collapsed across maternal adolescent exposure condition. ${ }^{\#} p<0.05$ compared to light phase within SAL-F0. ${ }^{*} p<0.02$ compared to SAL-F0 females within day. $N=15$ SAL-F0; $N=18$ MOR-F0. 
As expected, the frequency of pup grooming decreased while self-directed behaviors increased in the dark phase when compared to the light phase. These effects were similar across all postnatal days examined (see Figure 2; main effect of light phase, all $p s<0.05$ ). No significant effects of adolescent morphine exposure were observed on frequency of pup grooming or self-directed behaviors, nor were there any significant interactions (all ps $>0.1$ ).

\section{MATERNAL BEHAVIOR IN ADOLESCENT MORPHINE-EXPOSED FEMALES - DURATION}

As illustrated in Figure 3 (left panels), significant effects of both the light phase and maternal adolescent exposure were observed on PND5. All females nursed more during the light phase $\left[F_{(1,19)}=8.21\right.$, $p<0.05$ ], with no significant differences between MOR-F0 and SALF0 mothers $(p s>0.6)$. However, when we examined the amount of time female's spent hovering over their litter (i.e., contacting but not actively nursing pups), there was a significant main effect of light phase $\left[F_{(1,19)}=9.13, p<0.01\right]$ and maternal adolescent exposure $\left[F_{(1,19)}=8.93, p<0.01\right]$. Overall, MOR-F0 mothers spent more time hovering then SAL-F0 mothers. Finally, no significant effects on pup grooming were observed, while all females spent more time engaged in self-directed behaviors during the dark phase [main effect of light phase; $\left.F_{(1,19)}=17.4, p<0.01\right]$.

Few statistically significant effects were observed on PND12, however, some interesting trends were observed (see Figure 3, right panels). For example, while no significant effects of light phase or maternal adolescent exposure on nursing behavior were observed (both $p s>0.3$ ), there was a trend $\left[F_{(1,19)}=3.78, p=0.067\right]$ toward a light phase by maternal adolescent exposure interaction. This trend appears to be due to a tendency toward increased time spent nursing during the dark phase by MOR-F0 mothers. No significant effects on either hovering or pup grooming were observed. Finally, similar to the effects observed in PND5, all females engaged in more self-directed behaviors during the dark phase [main effect of light phase; $F_{(1,19)}=5.12, p<0.05$ ].

\section{SOCIAL PLAY BEHAVIOR IN THE OFFSPRING OF ADOLESCENT MORPHINE-EXPOSED MOTHERS}

Frequency and duration data were combined from separate measures to form two categories of social play behavior. These categories were (1) general social behavior, which included both social exploration and social grooming, and (2) rough and tumble play, which included pinning, boxing, wrestling, chasing, following, crawling over/under, and tail pulling. These data are shown in Figure 4. There was no significant effect of either sex or maternal adolescent exposure on either the frequency or duration of general social behaviors, although there was a modest trend toward a main effect of sex on durations $(p=0.07)$. Maternal adolescent exposure did, however, significantly affect both the frequency and duration of rough and tumble play. Moreover, these effects were sex-specific with a significant sex by maternal adolescent exposure interaction [frequency $-F_{(1,43)}=4.89, p<0.05$; duration $-F_{(1,43)}=5.2, p<0.03$ ]. Post hoc analyses indicate that these effects were largely due to the decreased expression of rough and tumble play by MOR-F1 males $(p<0.05)$. In addition to decreased play in MOR-F1 males, there was also a trend $(p=0.07)$ toward increased rough and tumble play in MOR-F1 females. Thus, significant sex differences were observed in MOR-F1 subjects (both $p s<0.03$ ), but not in SAL-F1 (both

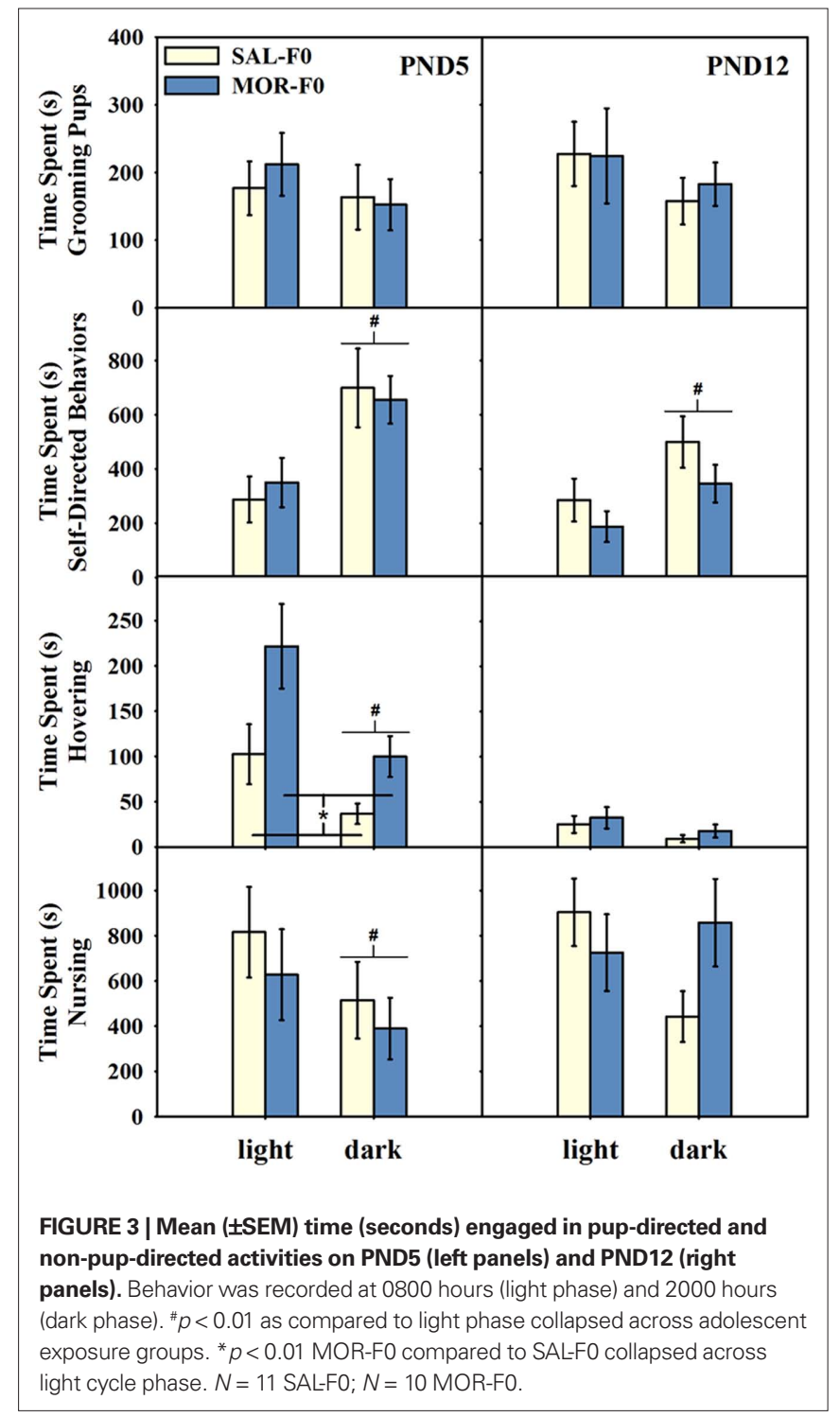

ps $>0.3)$. Overall, these findings demonstrate a sex-specific shift in rough and tumble play in MOR-F1 subjects, which is not associated with alterations in other aspects of social behavior at this age.

\section{DISCUSSION}

The current findings demonstrate that exposure to escalating doses of morphine, confined to the adolescent period, can induce subtle modifications in subsequent maternal care and can alter the behavioral phenotype of subsequent offspring. These effects were largely expressed as differences in frequency of nursing and contact time during early lactation. In addition, the offspring of MOR-F0 mothers showed sex-specific differences in rough and tumble play. These results indicate that even when opiates are withdrawn several weeks prior to mating, a history of opiate exposure can influence both maternal care and offspring development.

A number of animal models have documented the effects of changes in maternal care on developing offspring. For example, the amount of licking and grooming that a female exhibits in 

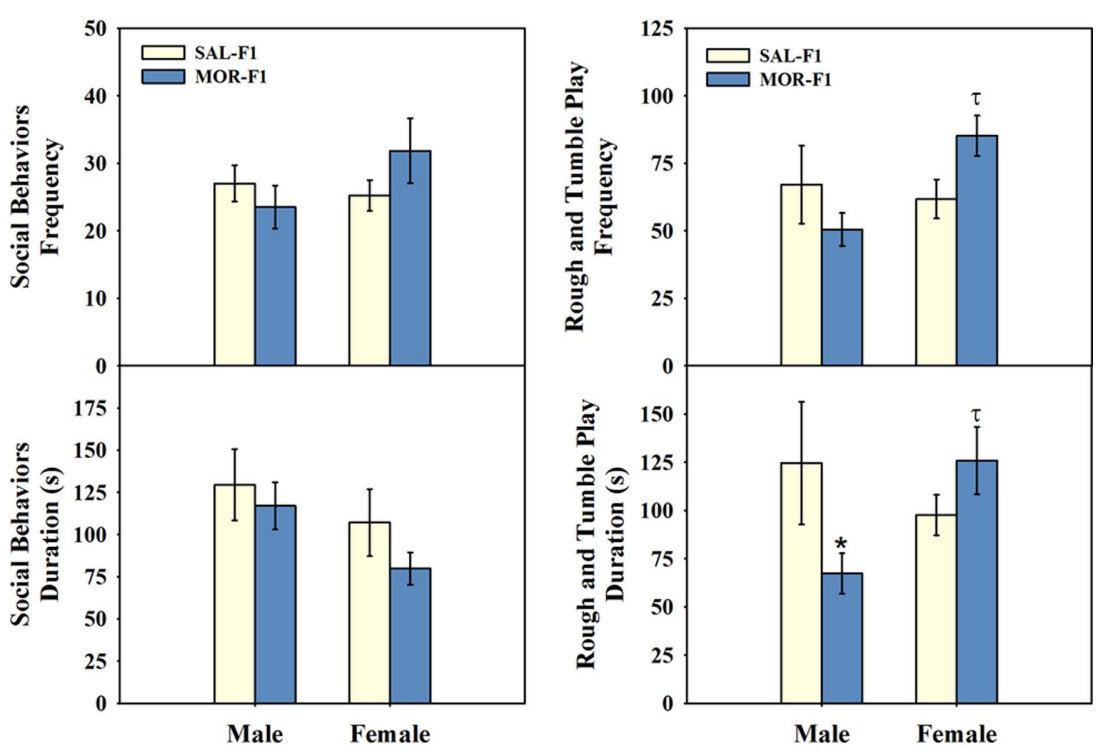

FIGURE 4 | Mean ( \pm SEM) frequency and duration (seconds) of either general social behaviors (left panels) or rough and tumble play (right panels) in the offspring of females exposed to either morphine (MOR-F1) or saline (SAL-F1) during adolescence. ${ }^{*} p<0.05$ as compared SAL-F1 males, ${ }^{\tau} p<0.05$ as compared to MOR-F1 males. $N=10$ SAL-F1 male; $N=10$ SAL-F1 female pairs and $N=12$ MOR-F1 male; $N=12$ MOR-F1 female pairs.

the first week postpartum, can modify the behavioral phenotype of her offspring (Caldji et al., 1998). These offspring effects include shifts in the maternal behavior of adult female offspring (Champagne et al., 2003; Kikusui et al., 2005), as well as changes in stress responsiveness (Fish et al., 2004), play behavior (Moore and Power, 1992), and cognition (Liu et al., 2000; Champagne et al., 2008). Other models, focusing on the effects of either brief or prolonged maternal separation, have also illustrated the importance of mother-offspring interactions (D'Amato et al., 1998), with significant effects on the regulation of fear and anxiety, stress responsiveness, and motivated behaviors observed in adult offspring (Romeo et al., 2003; Lee et al., 2007; Michaels et al., 2007; George et al., 2010; Skripuletz et al., 2010; Macri et al., 2011). Often, these effects are sex-specific (Slotten et al., 2006). It is not clear whether all of these alterations in offspring development are directly related to maternal behavior. It is certainly possible that a number of these effects are mediated by factors present in the milk (e.g., corticosterone or prolactin) or represent some interplay between maternal care, maternal endocrine milieu, and the offspring's own physiology. When considering how these findings might translate to human mothers and their infants, it is important to remember that there are significant developmental differences between rodents and humans. Indeed, neurodevelopment in the postnatal rat is comparable to that observed in second and third trimester infants (Bayer et al., 1993). By determining what mechanisms underlie changes in adult phenotype that are induced by alterations in maternal care, we may gain significant insight into how early life experience, both in utero and during the early postpartum period, may alter neurodevelopment. Overall, these findings on maternal care in rodents clearly indicate that even ostensibly modest changes in the postpartum environment can significantly impact offspring development.
How then might adolescent morphine exposure induce alterations in maternal care? One possible mechanism may be a shift in the endogenous opioid system. Indeed, we previously observed significant shifts in the regulation hypothalamic, opioid-related gene transcription following adolescent opioid exposure (Byrnes, 2008). These effects on gene transcription persisted for at least 10 weeks following cessation of morphine administration. Thus, a shift in endogenous opioid-mediated regulation of maternal behavior may be one consequence of adolescent morphine exposure.

The importance of endogenous opioids in both the pre- and postnatal period has been well documented. Opioids directly regulate numerous aspects of embryonic and fetal development (Kar and Quirion, 1995; Leslie et al., 1998; Zagon et al., 1999; Kivell et al., 2004; Cooney et al., 2009). Moreover, during pregnancy and parturition, endogenous opioids modulate both the maternal and fetal hypothalamic-pituitary-adrenal axis (Taylor et al., 1997; Douglas et al., 1998), and regulate maternal central oxytocin activity (Douglas et al., 1995; Douglas and Russell, 2001; Kutlu et al., 2004). The role of endogenous opioids in the regulation of specific aspects of maternal care in the rat is not well-defined. There is evidence, however, that the administration of an opioid antagonist increases the duration of nursing bouts and mother-offspring contact time during early lactation (Byrnes et al., 2000). These data fit well with the hypothesis that opioids regulate maternal-offspring attachment processes (Nelson and Panksepp, 1998; Weller and Feldman, 2003). Thus, in the face of opioid receptor blockade, the female may prolong contact and/or nursing bouts to achieve a similar level of reward associated with pup contact. In this context, one would postulate that MOR-F0 females may have more sensitive opioid receptors and therefore may terminate their nursing bouts sooner. While we observed significantly increased mu- and kappa-opioid receptor mRNA in non-lactating MOR-F0 females, no differences 
in the expression of these receptor subtypes were observed during lactation (Byrnes, 2008). Of course, protein expression and/or postsynaptic response of these receptors could be modified in MOR-F0 females. Moreover, our previous studies only examined changes in the mediobasal hypothalamus. Certainly, significant differences in opioid receptor number and/or function in any number of brain regions could underlie changes in nursing behavior during early lactation. This would not, however, explain the increased contact time (i.e., hovering) observed in MOR-F0 mother. Perhaps then, some other change in the female's behavior might underlie the observed effects on nursing frequency.

Examination of the differences in nursing behavior and contact time reveal a significant influence of both the time of day and the testing method. MOR-F0 females only spent more time away from the nest during the dark and these differences were only significant when tested using frequency data. Similarly, when recorded continuously, no decrease in the duration of nursing was observed during early lactation. One obvious difference between our frequency and duration data was the presence of an observer during frequency data collection. We have noticed that qualitatively, MOR-F0 females appear to be more sensitive to any disturbance in their environment. Thus, while all of our observations were conducted in the home cage, and care was taken not to disturb the female and her litter, MOR-F0 females would often come off the nest and rear up toward the front of the cage during the 30-min observation session. In addition, this behavioral pattern appeared more robust during the dark phase. Thus, the simple act of observing MOR-F0 females may have altered their nursing frequency. These effects would be more robust during early lactation when immature pups are unable to maintain nipple contact when the dam rears or changes positions. If a more general, non-specific, increase in "distractibility" underlies these changes in maternal care, this would suggest that MOR-F0 mothers may be more likely to decrease the care of their offspring in the presence of substantial environmental distracters.

The data on the duration of nursing suggests that during later postnatal time points, MOR-F0 mothers have more prolonged nursing bouts. As mentioned previously, during these later time points pups are more able to maintain nursing contact even when the female moves either within or even off of the nest. Thus, rearing up in the presence of any distracter would not be as detrimental to nursing when pups are older. However, this would not explain why the female nurses for longer periods when compared to SALF0 females. One possibility is that the female and/or offspring are compensating for decreased nutrition during early lactation with more sustained lactation during later development. Indeed, the bodyweight data demonstrate that MOR-F1 weanlings are heavier than their SAL-F1 counterparts. To what extent maternal nursing behavior, as opposed to some other metabolic factor, induces this difference in body weight is unknown. However, we have previous data suggesting differences in the lactogenic hormone prolactin in MOR-F1 mothers, with lower levels observed during early lactation and higher levels observed during late lactation (Byrnes, 2005b). Thus, MOR-F0 females may not necessarily be deficient in their nursing behavior, but rather may demonstrate a shift in the developmental profile of this behavior over the course of lactation. Overall, these data suggest that subtle modifications in maternal care, especially relating to nursing and non-nursing contact, are a consequence of adolescent morphine exposure. To what extent these differences play a role in the behavioral phenotype of their offspring remains to be determined.

In addition to modifying maternal care, adolescent morphine exposure induced transgenerational effects on juvenile play behavior. MOR-F1 males demonstrated a significant reduction in rough and tumble play, with no change in other aspects of social behavior (social grooming or exploration). In addition, there was a trend toward increased rough and tumble play behavior in MOR-F1 females, although these effects did not achieve significance. Rough and tumble play is displayed by a wide-range of species and is an important developmental marker (Auger and Olesen, 2009; Auger et al., 2011). It has been suggested that low levels of rough and tumble play may indicate vulnerability toward reduced motivated behavior in adulthood (Trezza et al., 2010). For example, animal models have demonstrated a relationship between rough and tumble play and future sexual and aggressive behaviors (van den Berg et al., 1999a; Cervantes et al., 2007; Wommack and Delville, 2007). Thus, decreased rough and tumble play in MOR-F1 males may suggest an increased risk for deficits in other motivated behavior in adulthood.

The neural systems underlying rough and tumble play have been fairly well elucidated (Gordon et al., 2002), with opioids playing a significant role in the regulation of this behavioral repertoire. Specifically, administration of morphine enhances play behavior, while administration of the mu-opiate receptor antagonist naloxone, reduces rough and tumble play (Panksepp et al., 1985; Vanderschuren et al., 1995; Guard et al., 2002; Trezza and Vanderschuren, 2008). Moreover, when juveniles are socially isolated, thereby eliminating all experiences of play, both mu and kappa receptors are significantly up-regulation in several nuclei related to emotional regulation (Van den Berg et al., 1999b). Thus, the reduction in rough and tumble play behavior could be a symptom of a down-regulation of functional mu-opiate receptors in MOR-F1 males or conversely, their low levels of play could induce alterations in opiate receptors. In line with these data, previous findings in adult MOR-F1 males, demonstrate significant alterations in their response to opiates (Byrnes, 2005a; Byrnes et al., 2011). Thus, one intriguing possibility is that MOR-F0 females transfer modifications in neural opioid systems to their offspring. The mechanism underlying this type of epigenetic effect is unknown, but could certainly involve alterations in maternal care or maternal endocrine milieu.

Finally, consideration of the current findings in the context of effects following prenatal morphine administration is warranted. Certainly, morphine exposure during the prenatal period has been shown to significantly impact offspring development (Sobrian, 1977; Vathy and Katay, 1992; Lesage et al., 1996; Vathy et al., 2000; Slamberova et al., 2005), with many of these effects involving changes in opioidergic function (O'Callaghan and Holtzman, 1976; Ramsey et al., 1993; Gagin et al., 1997; Chiou et al., 2003; Villarreal et al., 2008). Interestingly, the effects we observed in MOR-F1 animals are in the opposite direction of those observed in the offspring of females exposed to morphine in utero, with rough and tumble play behavior found to be increased in the offspring of females exposed to morphine during gestation ( $\mathrm{Hol}$ et al., 1996; Niesink et al., 1996). In fact, our effects are more similar to those observed 
following administration of opioid antagonists during fetal development (Shepanek et al., 1995; Medina Jimenez et al., 1997). Thus, the transgenerational effects observed in the offspring of adolescent morphine-exposed females may be indicative of a down-regulation of the endogenous opioid system in their mothers, perhaps both pre- and postnatally, which is then transmitted to their offspring via currently unidentified, epigenetic processes. Such processes could include modifications in maternal-offspring interactions.

\section{CONCLUSION}

Adolescent use of prescription pain relievers has increased dramatically in the past decade, especially in young females. Beyond the risks of overdose or addiction, the long-term effects of exposure to such powerful opiates during a critical period of neurodevelopment are unknown. As endogenous opioids play such a significant role in reproductive function, prior opiate use could influence pre- and/or postnatal factors. Given the importance of opioids in maternal-offspring interactions, and the critical role that mothers play in the healthy development of their children, it is possible that opiate use in adolescent girls could have

\section{REFERENCES}

Alemagno, S. A., Stephens, P., ShafferKing, P., and Teasdale, B. (2009). Prescription drug abuse among adolescent arrestees: correlates and implications. J. Correct. Health Care $15,35-46$.

Auger, A. P., Jessen, H. M., and Edelmann, M.N.(2011). Epigenetic organization of brain sex differences and juvenile social play behavior. Horm. Behav. 59, 358-363.

Auger, A. P., and Olesen, K. M. (2009). Brain sex differences and the organisation of juvenile social play behaviour. $J$. Neuroendocrinol. 21, 519-525.

Barr, C. S., Schwandt, M. L., Lindell, S. G., Higley, J. D., Maestripieri, D., Goldman, D., Suomi, S. J., and Heilig, M. (2008).Variation at the mu-opioid receptor gene (OPRM1) influences attachment behavior in infant primates. Proc. Natl. Acad. Sci. U.S.A. 105, 5277-5281.

Bayer, S. A., Altman J., Russo, R. J., and Zhang, X. (1993). Timetables of neurogenesis in the human brain based on experimentally determined patterns in the rat. Neurotoxicology 14, 83-144.

Bridges, R. S., and Grimm, C. T. (1982). Reversal of morphine disruption of maternal behavior by concurrent treatment with the opiate antagonist naloxone. Science 218, 166-168.

Byrnes, E. M. (2005a). Transgenerational consequences of adolescent morphine exposure in female rats: effects on anxiety-like behaviors and morphine sensitization in adult offspring. Psychopharmacology (Berl.) 182, 537-544.

Byrnes, E. M. (2005b). Chronic morphine exposure during puberty decreases postpartum prolactin secretion in adult female rats. Pharmacol. Biochem. Behav. 80, 445-451.

Byrnes, E. M. (2008). Chronic morphine exposure during puberty induces longlasting changes in opioid-related mRNA expression in the mediobasal hypothalamus. Brain Res. 1190, 186-192.

Byrnes, E. M., Rigero, B.A., and Bridges, R. S. (2000). Opioid receptor antagonism during early lactation results in the increased duration of nursing bouts. Physiol. Behav. 70, 211-216.

Byrnes, J. J., Babb, J. A., Scanlan, V. F., and Byrnes, E. M. (2011). Adolescent opioid exposure in female rats: transgenerational effects on morphine analgesia and anxiety-like behavior in adult offspring. Behav. Brain Res. 218, 200-205.

Cai, R., Crane, E., Poneleit, K., and Paulozzi, L. (2010). Emergency department visits involving nonmedical use of selected prescription drugs in the United States, 2004-2008. J. Pain Palliat. Care Pharmacother. 24, 293-297.

Caldji, C., Tannenbaum, B., Sharma, S. Francis, D., Plotsky, P.M., and Meaney, M. J. (1998). Maternal care during infancy regulates the development of neural systems mediating the expression of fearfulness in the rat. Proc. Natl. Acad. Sci. U.S.A. 95, 5335-5340.

Cervantes, M. C., Taravosh-Lahn, K., Wommack, J. C., and Delville, Y. (2007). Characterization of offensive responses during the maturation of play-fighting into aggression in male golden hamsters. Dev. Psychobiol. 49, 87-97.

Champagne, D. L., Bagot, R. C., van Hasselt, F., Ramakers, G., Meaney,

repercussions for future generations. To begin to elucidate the possible long-term effects of adolescent opiate use, animal models examining the impact of adolescent opiate exposure on both the female and her future offspring are required. The current findings demonstrate that exposure to increasing doses of morphine during adolescent development can induce subtle changes in maternal care and offspring development. While the neural and/or endocrine mechanisms underlying these effects remain to be determined, a shift in the endogenous opioid system of both mother and offspring seems likely. These findings strongly suggest that adolescent female opiate use, occurring prior to mating, and in the absence of any further use pre- or postnatally, can impact maternal-offspring interactions and the behavioral phenotype of their offspring. Thus, concerns about the impact of maternal drug use on children's health, should not only include consideration of in utero exposure, but prior drug history as well.

\section{ACKNOWLEDGMENT}

This work was supported by a grant from the National Institute on Drug Abuse R01 DA025674 (EMB).

M. J., de Kloet, E. R., Joels, M., and Krugers, H. (2008). Maternal care and hippocampal plasticity: evidence for experience-dependent structural plasticity, altered synaptic functioning, and differential responsiveness to glucocorticoids and stress. J. Neurosci. 28, 6037-6045.

Champagne, F. A., Francis, D. D., Mar, A. and Meaney, M. J. (2003). Variations in maternal care in the rat as a mediating influence for the effects of environment on development. Physiol. Behav. 79, 359-371.

Chiou, L. C., Yeh, G. C., Fan, S. H., How, C. H., Chuang, K. C., and Tao, P. L. (2003). Prenatal morphine exposure decreases analgesia but not $\mathrm{K}+$ channel activation. Neuroreport 14, 239-242.

Chiou, W. L., Robbie, G., Chung, S. M., Wu, T., and Ma, C. (1998). Correlation of plasma clearance of 54 extensively metabolized drugs between humans and rats: mean allometric coefficient of 0.66. Pharm. Res. 15, 1474-1479.

Cicero, T. J., Schmoeker, P. F., Meyer, E. R., Miller, B. T., Bell, R. D., Cytron, S. M., and Brown, C. C. (1986). Ontogeny of the opioid-mediated control of reproductive endocrinology in the male and female rat. J. Pharmacol. Exp. Ther. 236, 627-633.

Cooney, T. E., Konieczko, E. M., Roach, L., and Poole, B. (2009). Fate of mu receptors during rat skeletogenesis. Orthopedics 32, 95.

D'Amato, F. R., Cabib, S., Ventura, R., and Orsini, C. (1998). Long-term effects of postnatal manipulation on emotionality are prevented by maternal anxiolytic treatment in mice. Dev. Psychobiol. 32, 225-234.
Douglas, A. J., Bicknell, R. J., and Russell, J. A. (1995). Pathways to parturition. Adv. Exp. Med. Biol. 395, 381-394.

Douglas, A. J., Johnstone, H. A., Wigger, A., Landgraf,R., Russell,J.A., and Neumann, I. D. (1998). The role of endogenous opioids in neurohypophysial and hypothalamo-pituitary-adrenal axis hormone secretory responses to stress in pregnant rats. J. Endocrinol. 158, 285-293.

Douglas, A. J., and Russell, J. A. (2001). Endogenous opioid regulation of oxytocin and ACTH secretion during pregnancy and parturition. Prog. Brain Res. 133, 67-82.

Drolet, G., Dumont, E. C., Gosselin, I., Kinkead, R., Laforest, S., and Trottier, J.F. (2001). Role of endogenous opioid system in the regulation of the stress response. Prog. Neuropsychopharmacol. Biol. Psychiatry 25, 729-741.

Fish, E. W., Shahrokh, D., Bagot, R., Caldji, C., Bredy, T., Szyf, M., and Meaney, M. J. (2004). Epigenetic programming of stress responses through variations in maternal care. Ann. N. Y. Acad. Sci. 1036, 167-180.

Forman, R. F., Woody, G. E., McLellan, T., and Lynch, K. G. (2006). The availability of web sites offering to sell opioid medications without prescriptions Am. J. Psychiatry 163, 1233-1238.

Gagin, R., Kook, N., Cohen, E., and Shavit, Y.(1997). Prenatal morphine enhances morphine-conditioned place preference in adult rats. Pharmacol. Biochem. Behav. 58, 525-528.

George, E. D., Bordner, K. A., Elwafi, H. M., and Simen, A. A. (2010). Maternal separation with early weaning: a novel mouse model of early life neglect. BMC Neurosci. 11, 123. doi: 10.1186/1471-2202-11-123 
Goodman, G., Hans, S. L., and Cox, S. M. (1999). Attachment behavior and its antecedents in offspring born to methadone-maintained women. $J$. Clin. Child Psychol. 28, 58-69.

Gordon, N. S., Kollack-Walker, S., Akil, H., and Panksepp, J. (2002). Expression of $c$-fos gene activation during rough and tumble play in juvenile rats. Brain Res. Bull. 57, 651-659.

Guard, H. J., Newman, J. D., and Roberts, R.L. (2002). Morphine administration selectively facilitates social play in common marmosets. Dev. Psychobiol. 41, 37-49.

Gustafsson, L., Oreland, S., Hoffmann, P., and Nylander, I. (2008). The impact of postnatal environment on opioid peptides in young and adult male Wistar rats. Neuropeptides 42, 177-191.

Hol, T., Niesink, M., van Ree, J. M., and Spruijt, B. M. (1996). Prenatal exposure to morphine affects juvenile play behavior and adult social behavior in rats. Pharmacol. Biochem. Behav. 55, 615-618.

Janus, K. (1987). Early separation of young rats from the mother and the development of play fighting. Physiol. Behav. 39, 471-476.

Kalin, N. H., Shelton, S. E., and Lynn, D. E. (1995). Opiate systems in mother and infant primates coordinate intimate contact during reunion. Psychoneuroendocrinology 20, 735-742.

Kar, S., and Quirion, R. (1995). Neuropeptide receptors in developing and adult rat spinal cord: an in vitro quantitative autoradiography study of calcitonin gene-related peptide, neurokinins, mu-opioid, galanin, somatostatin, neurotensin and vasoactive intestinal polypeptide receptors. J. Comp. Neurol. 354, 253-281.

Kikusui, T., Isaka, Y., and Mori, Y. (2005). Early weaning deprives mouse pups of maternal care and decreases their maternal behavior in adulthood. Behav. Brain Res. 162, 200-206.

Kinsley, C. H., and Bridges, R. S. (1986). Opiate involvement in postpartum aggression in rats. Pharmacol. Biochem. Behav. 25, 1007-1011.

Kinsley, C. H., and Bridges, R. S. (1990). Morphine treatment and reproductive condition alter olfactory preferences for pup and adult male odors in female rats. Dev. Psychobiol. 23, 331-347.

Kinsley, C. H., Morse, A. C., Zoumas, C., Corl, S., and Billack, B. (1995). Intracerebroventricular infusions of morphine, and blockade with naloxone, modify the olfactory preferences for pup odors in lactating rats. Brain Res. Bull. 37, 103-107.

Kivell, B. M., Day, D. J., McDonald, F. J., and Miller, J. H. (2004).
Developmental expression of mu and delta opioid receptors in the rat brainstem: evidence for a postnatal switch in mu isoform expression. Brain Res. Dev. Brain Res. 148, 185-196.

Kreek, M. J. (2007). Opioids, dopamine, stress, and the addictions. Dialogues Clin. Neurosci. 9, 363-378.

Kutlu, S., Yilmaz, B., Canpolat,S., Sandal,S., Ozcan, M., Kumru, S., and Kelestimur, H. (2004). Mu opioid modulation of oxytocin secretion in late pregnant and parturient rats. Involvement of noradrenergic neurotransmission. Neuroendocrinology 79, 197-203.

Lee, J. H., Kim, H. J., Kim, J. G., Ryu, V., Kim, B. T., Kang, D. W., and Jahng, J. W. (2007). Depressive behaviors and decreased expression of serotonin reuptake transporter in rats that experienced neonatal maternal separation. Neurosci. Res. 58, 32-39.

Lesage, J., Bernet, F., Montel, V., and Dupouy, J.P. (1996). Effects of prenatal morphine on hypothalamic metabolism of neurotransmitters and gonadal and adrenal activities, during the early postnatal period in the rat. Neurochem. Res. 21, 723-732.

Leslie, F.M., Chen, Y., and Winzer-Serhan, U. H. (1998). Opioid receptor and peptide mRNA expression in proliferative zones of fetal rat central nervous system. Can. J. Physiol. Pharmacol. 76, 284-293.

Liu, D., Diorio, J., Day, J. C., Francis, D. D., and Meaney, M. J. (2000). Maternal care, hippocampal synaptogenesis and cognitive development in rats. Nat. Neurosci. 3, 799-806.

Macri, S., Zoratto, F., and Laviola, G. (2011). Early-stress regulates resilience, vulnerability and experimental validity in laboratory rodents through mother-offspring hormonal transfer. Neurosci. Biobehav. Rev. doi: 10.1016/j. neubiorev.2010.12.014 [Epub ahead of print].

Mann, P.E., Pasternak, G.W., and Bridges, R. S. (1990). Mu 1 opioid receptor involvement in maternal behavior. Physiol. Behav. 47, 133-138.

McCubbin, J. A. (1993). Stress and endogenous opioids: behavioral and circulatory interactions. Biol. Psychol. 35, 91-122.

Medina Jimenez, M., Lujan Estrada, M., and Rodriguez, R. (1997). Influence of chronic prenatal and postnatal administration of naltrexone in locomotor activity induced by morphine in mice. Arch. Med. Res. 28, 61-65.

Michaels, C. C., Easterling, K. W., and Holtzman, S. G. (2007). Maternal separation alters ICSS responding in adult male and female rats, but morphine and naltrexone have little affect on that behavior. Brain Res. Bull. 73 , 310-318.
Michaels, C. C., and Holtzman, S. G. (2008). Early postnatal stress alters place conditioning to both mu- and kappa-opioid agonists. J. Pharmacol. Exp. Ther. 325, 313-318.

Miranda-Paiva, C. M., Nasello, A. G., Yin, A. J., and Felicio, L. F. (2001). Morphine pretreatment increases opioid inhibitory effects on maternal behavior. Brain Res. Bull. 55 , 501-505.

Moore, C. L., and Power, K. L. (1992). Variation in maternal care and individual differences in play, exploration, and grooming of juvenile Norway rat offspring. Dev. Psychobiol. 25, 165-182.

Nelson, E. E., and Panksepp, J. (1998). Brain substrates of infant-mother attachment: contributions of opioids, oxytocin, and norepinephrine. Neurosci. Biobehav. Rev. 22, 437-452.

Niesink, R. J., Vanderschuren, L. J., and van Ree,J.M. (1996). Social play in juvenile rats after in utero exposure to morphine. Neurotoxicology 17, 905-912.

Niesink, R. J., and Van Ree, J. M. (1989). Involvement of opioid and dopaminergic systems in isolation-induced pinning and social grooming of young rats. Neuropharmacology 28, 411-418.

O'Callaghan, J. P., and Holtzman, S. G. (1976). Prenatal administration of morphine to the rat: tolerance to the analgesic effect of morphine in the offspring. J. Pharmacol. Exp. Ther 197, 533-544.

Panksepp, J., Jalowiec, J., DeEskinazi, F. G., and Bishop, P. (1985). Opiates and play dominance in juvenile rats. Behav. Neurosci. 99, 441-453.

Panksepp, J., Nelson, E., and Siviy, S. (1994). Brain opioids and motherinfant social motivation. Acta Paediatr. Suppl. 397, 40-46.

Paulozzi, L. J., Budnitz, D. S., and Xi, Y (2006). Increasing deaths from opioid analgesics in the United States. Pharmacoepidemiol. Drug. Saf. 15, 618-627.

Ramsey, N. F., Niesink, R. J., and Van Ree, J. M. (1993). Prenatal exposure to morphine enhances cocaine and heroin self-administration in drug-naive rats. Drug Alcohol Depend. 33, 41-51.

Reiter, E. O. (1987). Neuroendocrine control processes. Pubertal onset and progression. J. Adolesc. Health Care 8 , 479-491.

Romeo, R. D., Mueller, A., Sisti, H. M., Ogawa, S., McEwen, B. S., and Brake, W. G. (2003). Anxiety and fear behaviors in adult male and female C57BL/6 mice are modulated by maternal separation. Horm. Behav. 43, 561-567.

Rubin, B. S., and Bridges, R. S. (1984), Disruption of ongoing maternal responsiveness in rats by central administration of morphine sulfate. Brain Res. 307, 91-97.
Saltzman, W., and Maestripieri, D. (2010). The neuroendocrinology of primate maternal behavior. Prog. Neuropsychopharmacol. Biol. Psychiatry, doi:10.1016/j. pnpbp.2010.09.017

Schino, G., and Troisi, A. (1992). Opiate receptor blockade in juvenile macaques: effect on affiliative interactions with their mothers and group companions. Brain Res. 576, 125-130.

Shepanek, N. A., Smith, R. F., Anderson, L. A., and Medici, C. N. (1995). Behavioral and developmental changes associated with prenatal opiate receptor blockade. Pharmacol. Biochem. Behav. 50, 313-319.

Sizonenko, P. C. (1987). Normal sexual maturation. Pediatrician 14, 191-201.

Skripuletz, T., Kruschinski, C., Pabst, R., von Horsten, S., and Stephan, M. (2010). Postnatal experiences influence the behavior in adult male and female Fischer and Lewis rats. Int. J. Dev. Neurosci. 28, 561-571.

Slamberova, R., Riley, M. A., and Vathy, I. (2005). Cross-generational effect of prenatal morphine exposure on neurobehavioral development of rat pups. Physiol. Res 54, 655-660.

Slamberova, R., Szilagyi, B., and Vathy, I. (2001). Repeated morphine administration during pregnancy attenuates maternal behavior. Psychoneuroendocrinology 26, 565-576.

Slotten, H. A., Kalinichev, M., Hagan, J. J., Marsden, C. A., and Fone, K.C. (2006). Long-lasting changes in behavioural and neuroendocrine indices in the rat following neonatal maternal separation: gender-dependent effects. Brain Res. 1097, 123-132.

Sobrian, S. K. (1977). Prenatal morphine administration alters behavioral development in the rat. Pharmacol. Biochem. Behav. 7, 285-288.

Substance Abuse and Mental Health Services Administration (SAMHSA). (2007). Results from the 2006 National Survey on Drug Use and Health: National Findings. NSDUH Series H-32, DHHS Publication No. SMA 07-4293. Rockville, MD: Office of Applied Studies.

Substance Abuse and Mental Health Services Administration (SAMHSA). (2009). Results from the 2008 National Survey on Drug Use and Health: National Findings. NSDUH Series H-36, HHS Publication No. SMA 09-4434. Rockville, MD: Office of Applied Studies.

Sukikara, M. H., Platero, M. D., Canteras, N. S., and Felicio, L. F. (2007). Opiate regulation of behavioral selection during lactation. Pharmacol. Biochem. Behav. 87, 315-320. 
Sung, H. E., Richter, L., Vaughan, R., Johnson, P. B., and Thom, B. (2005). Nonmedical use of prescription opioids among teenagers in the United States: trends and correlates. J. Adolesc. Health 37, 44-51.

Taylor, C. C., Wu, D., Soong, Y., Yee, J. S., and Szeto, H. H. (1997). Opioid modulation of the fetal hypothalamicpituitary-adrenal axis: the role of receptor subtypes and route of administration. J. Pharmacol. Exp. Ther. 281, 129-135.

Trezza, V., Baarendse, P. J., and Vanderschuren, L. J. (2010). The pleasures of play: pharmacological insights into social reward mechanisms. Trends Pharmacol. Sci. 31, 463-469.

Trezza, V., and Vanderschuren, L. J. (2008). Cannabinoid and opioid modulation of social play behavior in adolescent rats: differential behavioral mechanisms. Eur. Neuropsychopharmacol. 18, 519-530.

van den Berg, C. L., Hol, T., Van Ree, J. M., Spruijt, B. M., Everts, H., and Koolhaas, J. M. (1999a). Play is indispensable for an adequate development of coping with social challenges in the rat. Dev. Psychobiol. 34, 129-138.

Van den Berg, C. L., Van Ree, J. M., Spruijt, B. M., and Kitchen, I. (1999b). Effects of juvenile isolation and morphine treatment on social interactions and opioid receptors in adult rats: behavioural and autoradiographic studies. Eur. J. Neurosci. 11,3023-3032.

Van den Berg, C. L., Van Ree, J. M., and Spruijt, B.M. (2000). Morphine attenuates the effects of juvenile isolation in rats. Neuropharmacology39, 969-976.

Vanderschuren, L. J., Niesink, R. J. Spruijt, B. M., and Van Ree, J. M. (1995). Effects of morphine on different aspects of social play in juvenile rats. Psychopharmacology (Berl.) 117, 225-231.

Van Ree, J. M., Niesink, R. J., Van Wolfswinkel, L., Ramsey, N. F., Kornet, M. M., Van Furth, W. R., Vanderschuren, L. J., Gerrits, M. A., and Van den Berg, C. L. (2000). Endogenous opioids and reward. Eur. J. Pharmacol. 405, 89-101.

Vathy, I., He, H. J., Iodice, M., Hnatczuk, O. C., and Rimanoczy, A. (2000). Prenatal morphine exposure differentially alters $\mathrm{TH}$-immunoreactivity in the stress-sensitive brain circuitry of adult male and female rats. Brain Res. Bull. 51, 267-273.

Vathy, I., and Katay, L. (1992). Effects of prenatal morphine on adult sexual behavior and brain catecholamines in rats. Brain Res. Dev. Brain Res. 68, 125-131.

Veenema, A. H., and Neumann, I. D. (2009). Maternal separation enhances offensive play-fighting, basal corticosterone and hypothalamic vasopressin mRNA expression in juvenile male rats. Psychoneuroendocrinology 34, 463-467.

Villarreal, D. M., Derrick, B., and Vathy, I. (2008). Prenatal morphine exposure attenuates the maintenance of late LTP in lateral perforant path projections to the dentate gyrus and the CA3 region in vivo. J. Neurophysiol. 99, 1235-1242.

Weaver, S. A., Diorio, J., and Meaney, M. J. (2007). Maternal separation leads to persistent reductions in pain sensitivity in female rats. J. Pain. 8, 962-969.

Weller, A., and Feldman, R. (2003). Emotion regulation and touch in infants: the role of cholecystokinin and opioids. Peptides 24, 779-788.

Wommack, J. C., and Delville, Y. (2007). Stress, aggression, and puberty: neuroendocrine correlates of the development of agonistic behavior in golden hamsters. Brain Behav. Evol. 70, 267-273.

Wu, L. T., Pilowsky, D. J., and Patkar, A. A. (2008). Non-prescribed use of pain relievers among adolescents in the United States. Drug Alcohol Depend. 94, 1-11.

Zager, E. L., and Black, P. M. (1985). Neuropeptides in human memory and learning processes. Neurosurgery 17, 355-369.
Zagon, I. S., Wu, Y., and McLaughlin, P. J. (1999). Opioid growth factor and organ development in rat and human embryos. Brain Res. 839, 313-322.

Conflict of Interest Statement: The authors declare that the research was conducted in the absence of any commercial or financial relationships that could be construed as a potential conflict of interest.

Received: 25 February 2011; paper pending published: 19 March 2011; accepted: 08 May 2011; published online: 06 June 2011. Citation: Johnson NL, Carini L, Schenk ME, Stewart $M$ and Byrnes EM (2011) Adolescent opiate exposure in the female rat induces subtle alterations in maternal care and transgenerational effects on play behavior. Front. Psychiatry 2:29. doi: 10.3389/fpsyt.2011.00029

This article was submitted to Frontiers in Child and Neurodevelopmental Psychiatry, a specialty of Frontiers in Psychiatry.

Copyright (C) 2011 Johnson, Carini, Schenk, Stewart and Byrnes. This is an open-access article subject to a non-exclusive license between the authors and Frontiers Media $S A$, which permits use, distribution and reproduction in other forums, provided the original authors and source are credited and other Frontiers conditions are complied with. 